\title{
Correction to: The argument from almost indiscernibles
}

\section{Gonzalo Rodriguez-Pereyra ${ }^{1}$ (D)}

\section{Correction to: Philos Stud (2017) 174:3005-3020 https://doi.org/10.1007/s11098-016-0843-8}

In pages 3005 (abstract), 3006 and 3019, there is a sentence that begins: "If the premise lacks support, the argument does not establish the possibility of almost indiscernibles..."

The beginning of the sentence should instead read: "If the premise lacks support, the argument does not establish the possibility of indiscernibles..."

The author acknowledges responsibility for this error.

The original article can be found online at https://doi.org/10.1007/s11098-016-0843-8.

Gonzalo Rodriguez-Pereyra

gonzalo.rp21@gmail.com; gonzalo.rodriguez-pereyra@oriel.ox.ac.uk

1 Oriel College, University of Oxford, Oxford OX14EW, UK 